\title{
DO COMUM DA EDUCAÇÃO AMBIENTAL À EDUCAÇÃO AMBIENTAL DO COMUM
}

\author{
RODRIGO BARCHI ${ }^{1}$ \\ ORCID: https://orcid.org/0000-0001-9198-1382
}

\begin{abstract}
RESUMO: A partir da noção de Michael Hardt e Antonio Negri de que o comum não é só terra compartilhada, mas linguagens criadas, práticas sociais estabelecidas, modos de sociabilidade e produção intelectual coletiva, esse texto busca tanto discutir a educação ambiental como um campo comunal de pesquisa e de militância na ecologia e na educação, quanto pensar o comum como espaço privilegiado de criação e exercício de perspectivas ecologistas em educação. O artigo é resultado parcial de uma pesquisa teórica e conceitual, e se divide em quatro partes. A primeira uma apresentação do conceito "noções comuns" em Spinoza e na leitura de alguns de seus comentadores; a segunda busca compreender a influência das "noções comuns" sobre a elaboração do conceito de comum na obra conjunta de Hardt e Negri, e o debate realizado sobre o mesmo na obra de Dardot e Laval. Na terceira parte intenciona-se pensar a criação, produção e disseminação da educação ambiental no Brasil como resultado das ações e pensamentos em comum dos educadores e militantes ecologistas. E na quarta parte, busca-se construir, a partir da proposta das Perspectivas Ecologistas em Educação, especialmente na obra de Reigota, algumas conexões conceituais para pensar nas educações ambientais como exercício político construído para o comum.
\end{abstract}

Palavras-chave: Noções Comuns, Educação Ambiental, perspectivas ecologistas em educação, Comum, Ecologia Política.

\section{FROM THE COMMON OF ENVIRONMENTAL EDUCATION TO ENVIRONMENTAL EDUCATION OF THE COMMON}

\begin{abstract}
Based on the notion of Michael Hardt and Antonio Negri that the common is not only shared land, but created languages, established social practices, modes of sociability and collective intellectual production, this text seeks to discuss environmental education as a communal field of research and militancy in ecology and education, and to think the common as a privileged space for the creation and exercise of ecological perspectives in education. The article is the partial result of theoretical and conceptual research, and is divided into four parts. The first one presents the concept of "common notions" in Spinoza and in the reading of some of his commentators; the second seeks to understand the influence of the "common notions" on the elaboration of the concept of common in the joint work of Hardt and Negri, and the debate about it in the work of Dardot and Laval. In the

\footnotetext{
${ }^{1}$ Universidade Federal do Rio Grande (FURG), Rio Grande, RS, Brasil.

Doutor em Filosofia e História da Educação pelo Programa de Pós-Graduação em Educação da Universidade Etadual de Campinas (UNICAMP). Professor do Programa de Pós-Graduação em Educação da Universidade Ibirapuera (UNIB), São Paulo, SP, Brasil. Pós-Doutorando do Programa de Pós-Graduação em Educação em Ciências da Universidade Federal do Rio Grande (FURG), Rio Grande, RS, Brasil. Email: rodrigo.barchi@ibirapuera.edu.br. 
third part it intends to think about the creation, production and dissemination of environmental education in Brazil as a result of the actions and thoughts in common of educators and environmental activists. And in the fourth part, it seeks to build, from the proposal of the Ecological Perspectives in Education, especially in the work of Reigota, some conceptual connections to think of environmental education as a political exercise built for the common.

Key Words: Common Notions, Environmental Education, ecology perspectives in education, Common, Political Ecology

\section{DEL COMÚN DE LA EDUCACIÓN AMBIENTAL A LA EDUCACIÓN AMBIENTAL DEL COMÚN}

RESÚMEN: Partiendo de la noción de Michael Hardt y Antonio Negri de que lo común no es solo tierra compartida, sino lenguajes creados, prácticas sociales establecidas, modos de sociabilidad y producción intelectual colectiva, este texto busca discutir tanto la educación ambiental como un campo comunal de investigación y militancia en ecología y educación, como pensar en lo común como un espacio privilegiado para crear y ejercer perspectivas ecológicas en la educación. El artículo es un resultado parcial de la investigación teórica y conceptual, y se divide en cuatro partes. La primera una presentación del concepto "nociones comunes" en Spinoza y en la lectura de algunos de sus comentaristas; la segunda busca comprender la influencia de las "nociones comunes" en la elaboración del concepto de común en la obra conjunto de Hardt y Negri, y el debate realizado sobre el tema en la obra de Dardot y Laval. La tercera parte tiene la intención de pensar en la creación, producción y difusión de la educación ambiental en Brasil como resultado de las acciones y pensamientos comunes de educadores y activistas ambientales. Y en la cuarta parte, busca construir, desde las Perspectivas Ecologistas en Educación, especialmente en la obra de Reigota, algunas conexiones conceptuales para pensar en las educaciones ambientales como un ejercicio político construido para el común.

Palabras clave: Nociones comunes, Educación Ambiental, perspectivas de la ecología en la educación, Común, Ecología Política

\section{INTRODUÇÃO}

Nas primeiras linhas da introdução ao inacabado Tratado Político, Baruch Spinoza (2009) execra a filosofia política voltada para o estabelecimento de um modelo humano perfeito de conduta moral. Chama esse pensamento de Sátira e/ou no máximo uma Quimera utópica fadada ao profundo fracasso. Critica também os políticos, que ao fazerem justamente um exercício contrário, ou seja, de impedir a possibilidade de transformação da "essência humana" - sempre viciada e desordenada - para que nunca deixasse de haver a necessidade de imposição de regulações aos corpos e coletivos humanos, mantivessem o status político de dominação e manipulação. Spinoza sugeria outra alternativa, a de observar os seres humanos justamente a partir de sua natureza, sujeita às paixões e aos desejos, para que pudesse construir uma filosofia política apropriada ao que chamava de natureza humana, elaborando, em seguida, uma análise daquilo que poderia ser o melhor sistema político para as sociedades humanas.

Essa recusa de Spinoza às narrativas utópicas e fatalistas também está presente na Ética, onde ele entendia que o verdadeiro conhecimento das coisas precisa ser construído, em primeiro lugar, a partir do mundo em sua materialidade e imanência. Não de narrativas fantásticas de poderes externos ao universo, mas daquilo que está intrinsecamente ligado à existência física dos seres e das coisas. Em outras palavras, daquilo que há em comum a todas as coisas no universo.

Nesse sentido, a partir da noção de comum no pensamento político de Spinoza e, principalmente, do uso que alguns de seus intérpretes mais recentes fizeram do conceito de comum do filósofo português radicado na Holanda, este ensaio é uma tentativa de pensar a educação ambiental a partir da utilização dessa ideia de comum como ferramenta conceitual tanto para compreender os fatores que a levaram não somente a ser entendida como campo da ciência e da educação, mas como 
elemento constituidor da ecologia política, em especial no Brasil; e também como ela tem, em sua intenção de transformação radical da realidade - principalmente no embate que ela, em sua rebeldia, provoca contra os exercícios da governamentalidade liberal - a necessidade de produzir-se constantemente, como um exercício do comum.

$\mathrm{O}$ artigo é desenvolvido em quatro partes.

$\mathrm{Na}$ primeira, a partir da análise que alguns intérpretes do pensamento de Spinoza, entre os quais Deleuze (2002; 2017), Negri (1993; 2016; 2019) e Chauí (2003; 2011; 2016) e principalmente do que está exposto em Ética, é apresentado o conceito de noções comuns, as quais, também chamadas de segundo gênero de conhecimento, são consideradas pelo pensador luso-holandês como uma forma de conhecimento adequado, sendo capazes de compreender o mundo a partir de sua materialidade, sem se submeter às ideias inadequadas ou noções supersticiosas e preconceituosas de perceber o mundo. Nessa parte também há uma aproximação entre esse conceito de noções comuns e o perspectivismo de Viveiros de Castro $(2002 ; 2015)$ que ao final do texto servirá para fundamentar a proposta de educação ambiental do comum como encontro de singularidades e diferenças.

Na segunda parte, é desenvolvido o conceito de comum como noção de construção das coletividades e ação política, especialmente a partir da obra de Hardt e Negri (2005; 2016; 2018), que é fortemente influenciada por Spinoza. Mas também a partir da elaboração da ideia do comum como entrelace de lutas sociais, culturais e econômicas, proposta por Dardot e Laval (2017). O comum aqui é pensado não somente como o que é produzido comunalmente pelas sociedades humanas e cooptado pelos agentes e instituições de poder, mas como força política de resistência, insubmissão, luta e potencialização de alternativas de vivência.

Em seguida, busca-se compreender a criação e o desenrolar da educação ambiental, em especial no Brasil, utilizando o conceito de comum como um catalisador político de encontros de múltiplas reivindicações e manifestações. Sugere-se aqui pensar, de um lado, a ecologia política como um conjunto de diferentes ações em defesa do meio ambiente e, de outro, como a educação ambiental e as(os) educadoras(es) ambientais foram, em comum, influenciados e conectados nesse campo. É no sentido de produção coletiva de saberes, e não de uma noção ou missão divina, que esse texto busca entender a proliferação de pensamento e ação ao redor dessa área.

Por fim, há uma discussão sobre a possibilidade de práxis ecológica na educação voltada ao comum. A proposta de utilização do conceito de perspectivas ecologistas em educação, associado à educação ambiental, é desenvolvida aqui mais como ação epidêmica no campo da educação, no sentido de proliferação da ecologia na práxis educativa, do que necessariamente uma perspectiva isolada e/ou exótica de atividade e pensamento exterior ao fazer educativo dentro e fora do espaço escolar.

\section{UM ANIMAL COMUM}

Há uma conhecida e polêmica peleja na construção do conhecimento das Ciências Naturais e da Biologia, em especial a Zoologia, que é a discussão entre Georges Cuvier (1769-1832) e Etienne Geoffroy Saint Hilaire (1772-1844), que marcou a forma como os estudos de anatomia e morfologia animal seriam compreendidos no decorrer do século XIX, influenciando, inclusive, os debates entre Darwin e Owen sobre os conceitos de homologia e analogia na evolução natural (OCHOA; BARAHONA, 2009).

Enquanto Cuvier compreendia que a anatomia comparada, fortemente influenciada pela teleologia aristotélica, era ainda a melhor forma de compreender e classificar os animais a partir de suas diferenças de formas, em seus usos e fins, Saint Hilaire sugeria que havia um arquétipo comum, um princípio de unidade de composição e de plano, o qual significava que todos os seres viventes estavam sob um mesmo fundo material, e que todos os órgãos e estruturas eram variações de um mesmo sistema. Não tendo, portanto, necessariamente, um fim em si (SAINT HILAIRE, 2009; OCHOA; BARAHONA, 2009).

Saint Hilaire evoca Leibniz para reforçar, em sua filosofia zoológica, a noção de que os animais são "produto do mesmo sistema de composição, em um arranjo de partes orgânicas que, de modo uniforme, sempre se repetem" (SAINT HILAIRE, 2009, p. 78), tendo, portanto, muito mais em 
comum entre si do que sugeria a proposta aristotélica adotada não somente por Cuvier, mas por toda a construção do conhecimento ocidental durante mais de dois milênios. A qual, apesar de considerar a ideia do ancestral comum, focava muito mais naquilo que os órgãos tenham de diferente do que em comum.

No entanto, Deleuze (2017) sugere que, mais do que ter Leibniz como expoente citado pelo próprio Saint-Hilaire, a proposta de entender a natureza inteira como um único animal tem como precursor principal o filósofo Spinoza (1632-1677). Ao sugerir um Saint-Hilaire mais spinozista do que leibniziano, Deleuze argumenta que o naturalista francês se propõe muito mais a analisar "as similitudes inteligíveis" do que necessariamente as "diferenças sensíveis" (DELEUZE, 2017, p. 311), tirando do exame dos órgãos e componentes corporais suas finalidades funcionais para dar lugar às variações nos modos de conexão entre as partes. Em outras palavras, cada órgão e cada animal deixam de ter uma essência pressuposta sedentária, transcendental e cristalizada a partir da definição da função de suas partes, para serem observados como modos variáveis na composição do grande animal composto pela natureza. Para Spinoza, Deus, ou seja, Natureza.

Anos depois, em companhia de Guattari, Deleuze sugere que esse sistema ou plano de composição pode ser pensado e compreendido como aquilo que definiu como plano de imanência:

Em todo caso, puro plano de imanência, de univocidade, de composição, onde tudo é dado, onde dançam elementos e materiais não formados que só se distinguem pela velocidade, e que entram nesse ou naquele agenciamento individuado de acordo com suas conexões, suas relações de movimentos. Plano fixo da vida, onde tudo mexe, atrasa ou se precipita. Um só Animal abstrato para todos os agenciamentos que o efetuam. Um só e mesmo plano de consistência ou de composição para o cefalópode e o vertebrado, pois bastaria o vertebrado dobrar-se em dois suficientemente rápido para soldar os elementos das metades de suas costas, aproximar sua bacia de sua nuca, e juntar seus membros a uma das extremidades do corpo, tornando-se assim, Polvo ou Sépia, tal "um saltimbanco que joga seus ombros e sua cabeça pra trás para andar sobre sua cabeça e suas mãos” (DELEUZE; GUATTARI, 1997, p. 40)

Tanto quanto um saltimbanco brincando de caranguejo ou siri, ou mesmo os meninos e meninas pichadores(as) brincando de lagartixa ou aranha nas paredes e bordas dos edifícios das metrópoles, esse posicionamento de Deleuze e Guattari, sobre a compreensão do mundo estar presente nas diferenciações de velocidades e intensidades, e não mais nas funcionalidades pré-concebidas e teleológicas impostas por transcendências exteriores ao mundo, permite aqui o risco de elaborar uma analogia com a perspectiva de mundo de algumas cosmologias ameríndias e etnografias amazônicas. As quais também propõe a inversão da forma como os humanos veem os animais e o mundo, assim como os animais veem o humano e o mundo.

Ao sugerir o perspectivismo como a capacidade de ocupar um ponto de vista, Viveiros de Castro (2002) propõe não mais as propriedades fixas de uma espécie ou outra, mas o grau e a situação como categorias de análise. Isso devido à compreensão na qual, para as narrativas míticas dos povos ameríndios, não há diferenciação original entre os humanos e os animais, sendo a condição original de todos os últimos a humanidade (VIVEIROS DE CASTRO, 2002, p. 355).

Explica o antropólogo brasileiro que o xamanismo, ao buscar compreender o Outro, vestindo a vestimenta do Outro e se pondo em seu lugar, atravessando barreiras corpóreas, tenta conhecer o Outro a partir de seu ponto de vista, e não de quem está fora. Visto que, apesar das diferenças entre os sujeitos e os objetos na epistemologia ocidental, na construção do saber ameríndio, "um objeto é um sujeito incompletamente sujeitado" (VIVEIROS DE CASTRO, 2002, p. 360). Nesse sentido:

Conhecer, assim, é dessubjetivar, explicitar a parte do sujeito presente no objeto, de modo a reduzi-la a um mínimo ideal. Os sujeitos, tanto quanto os objetos, são vistos como resultantes de processos de objetivação: o sujeito se constitui ou reconhece a si mesmo nos objetos que produz, e se conhece objetivamente quando consegue se ver "de fora", como um "isso". Nosso jogo epistemológico se chama objetivação: o que não foi objetivado permanece irreal e abstrato. A forma do Outro é a coisa” (VIVEIROS DE CASTRO, 2002, p. 358). 
Ao recusar a separação extrema entre sujeito e objeto, e entender que mais do que funcional ou intrínseca, a sua diferença é de perspectiva e intensidade, recusando, inclusive, a constante separação entre natureza e cultura, as práticas ameríndias (tanto no xamanismo como no animismo), ao assumirem o olhar do animal, o entendem como sujeito - pois também é humano - e reconhecem nele muito mais coisas em comuns do que em diferenças essencialmente pressupostas.

Nesse sentido, esse perspectivismo - que recebe forte influência do pensamento deleuziano - adota a natureza como um plano de composição, um território do comum, onde há mais similitudes entre os seres do que diferenças, as quais estão mais nas velocidades e movimentos do que nas formas e nas funções, pois permite que seja possível entender a condição animal muito mais próxima aos humanos, por entender o humano como modo da natureza.

Por isso também que Deleuze (2017) afirma que as noções comuns de Spinoza são mais biológicas que exatas, pois, ao termos noção daquilo que é nosso corpo e o habita, também temos noção daquilo que está no corpo dos outros. Menos do que serem comuns a todos os espíritos, elas são é comuns aos corpos, exprimindo relações de conveniência ou de composição dos corpos (DELEUZE, 2002).

Para Spinoza, as noções comuns são ideias adequadas, pois elas não estão referidas à mente singular de alguém (EII, P. 36), mas aos elementos que podem ser concebidos como comuns a todas as coisas (EII, P. 38), e em especial, a todos os homens (EII, P. 38, Dem.). As noções comuns são consideradas ideias adequadas para o filósofo luso-holandês, pois são referentes aquilo que é comum e próprio que afeta aos seres humanos.

As noções comuns são consideradas como razão ou conhecimento de segundo gênero, que, junto à ciência intuitiva (conhecimento de terceiro gênero), são tidas por Spinoza como ideias adequadas, pois não criam as confusões e inadequações criadas pela superstição e pelas ideias de primeiro gênero, como as experiências errantes e os signos (EII, P. 41, Dem.), mas "vai de premissas a consequências e se apoia em axiomas claros e distintos" (ONFRAY, 2009, p. 250)

Não há nenhuma afecção, e consequentemente afeto, sobre o corpo, do qual não se possa formar uma ideia "clara e distinta", e, por isso mesmo, sugere Hardt (1996), analisando a obra de Deleuze sobre Spinoza, que mais do que um conhecimento especulativo daquilo que forma o sujeito, as noções comuns são exercício político, ativo e alegre de constituição ética (HARDT, 1996, p. 157). Pois, ao conseguir conhecer o que afeta o corpo como aquilo que pode enfraquecer ou fortalecer (as afecções passivas tristes e as alegres), o sujeito pode tornar-se ativo, capaz de ser cada vez mais livre para construir o próprio ser.

Ao recordar da carta 32 de Spinoza, direcionada à Oldenburg (SPINOZA, 2014), Chaui (2016), enaltece a questão da parte e do todo, lembrando a parte como aquela que está em uma relação determinada e constante com as outras partes, submetida à ação e causas do conjunto, enquanto o todo, determinante do que se passa em seus elementos, não sobre mudanças externas, visto que não há ação externa na natureza-Deus infinita.

Ser parte, portanto, é estar numa relação concordante, comunicante e constante com outras que possuem as mesmas propriedades que ela - e é este o sentido do "comum a todas as coisas". Por outro lado, tomada como um todo, a parte é constituída por propriedades comuns às suas partes, que mantêm entre si relações de concordância, constância e comunicação, pois ser um todo é determinar-se a si mesmo e determinar todas as operações das partes constituintes - e é este o sentido de estar igualmente "nas partes e no todo" (CHAUÍ, 2016, p. 239-240)

As noções comuns, reforça Chaú, não são os universais abstratos, que são gerados em uma mente externamente determinada, mas fundamentos ontológicos e físicos do que é o comum, e só uma mente internamente disposta a não se submeter às confusões daquilo que dá origem ao primeiro gênero de conhecimento, causador de preconceitos e superstições, é capaz de dar conta de compreender essas noções comuns (CHAUÍ, 2016, p. 240). Especificamente sobre a natureza humana, Chauí afirma que sua noção comum não tem uma imagem, muito menos um transcendental, que precisa ser buscado na 
essência divina daquilo que a filosofia platônico-aristotélica tanto insistiu, mas uma ideia adequada daquilo que convêm tanto às partes, quanto ao todo (CHAUÍ, 2011, p. 231). A necessidade de uma concepção materialista do humano, uma reversão da perspectiva metafísica e uma radical imanência caracterizam o que Negri chama de antiplatonismo ontológico de Spinoza (NEGRI, 1993, p. 184).

Para que o veneno e o sangue entrem em relação, ou para que a constelação do Cachorro entre em relação com o vira-lata nas noites estreladas ao relento (SUHAMY, 2016), ou ainda para que os animais predadores, como o jaguar, vejam os seres humanos como espíritos ou animais predadores (VIVEIROS DE CASTRO, 2015, p. 44), é preciso que tenham propriedades em comum, possíveis de, alguma forma, as fazerem se relacionar. Pois, como afirma Zourabchilili (2014), somente se essas propriedades estiverem em comum na extensão, como atributo da natureza que as envolve, poderão, na mente humana, tornarem-se adequadas.

Apesar das noções comuns não esgotarem o poder de conhecer dos seres humanos (DELBOS, 2016, p. 76) e serem condição para a passagem ao terceiro gênero de conhecimento - ou seja, a ciência intuitiva - a intenção desse texto é somente discutir o conceito do comum, tanto a partir da presença das noções comuns na Ética de Spinoza, e da compreensão que alguns de seus intérpretes buscam no comum como um catalisador para a ação política, para tentar promover uma discussão de como essa ideia pode nos fazer pensar a educação ambiental - ou as educações ambientais, em sua pluralidade - como ação política e pedagógica surgida no agir e pensar em comum de educadores e ecologistas.

A proposta aqui, a partir da apresentação do conceito de noções comuns como precursor da discussão realizada por Negri e Hardt ao redor do comum, é justamente pensar o comum como um elemento precursor e definidor da construção das educações ambientais, sendo estas compreendidas como uma multiplicidade de movimentos políticos no âmbito da educação e da ecologia política. É buscar compreender a potência do agir coletivo de diversos interesses em comum, cujas ações tem como intenções desde proteger as araras azuis, até nos fazer entender a produção de uma nova era geológica que convencionou-se chamar de Antropoceno (SAMPAIO, 2019). Ou então, ainda, simplesmente impedir ou adiar o fim do mundo...

\section{COMUM COMO AÇÃO POLÍTICA}

Comum, sugere Chauí na leitura da segunda parte da Ética, "é uma propriedade ou qualidade possuída por todas as partes de um mesmo todo" (CHAUÍ, 2003, p. 146). Ou seja, não são essências em comum - sendo essas como as singularidades materiais, concretas e atuais, não transcendentes ou preconcebidas, mas potências de agir (CHAUÍ, 2003) e ações em comum. Se a noção comum é aquela que identifica aquilo que é comum ao corpo humano e aos corpos exteriores, como afirma (SPINOZA, 2017, EII, P39, Dem. p. 79), agir em comum é aquilo que numa mesma ação transforma as partes em constituintes do todo (CHAUí, 2003).

A constituição desse corpo político do agir em comum não se limita somente àquilo que atém aos bens comuns, mas a "autovaloração das singularidades no seio da multidão e a composição do comum como um projeto de produção e de vida 'eterna"' (NEGRI, 2019, p. 91). Comum não somente como um espaço político imposto por decretos, normas, leis e instituições disciplinares, ou seja, Civitas, Estado, Nação, e, como sugere Stern (2016, p. 195), "instituições de sequestro". Mas um comum que seja "produtor e produto das formas de vida" (NEGRI, 2019, p. 87), de relações entre elas. Consequentemente, de ecologias. Para Dardot e Laval, o comum pensado como co-atividade, e não como co-pertencimento, copropriedade ou copossessão, pensando o comum não como um bem apesar do pensamento de Spinoza, ao tratar as noções comuns e o comum como racionais, em um caminho para aquilo que é o bom - mas como co-ação, agir em comum. (DARDOT; LAVAL, 2017, p. $52-53)$

O comum, para Negri (2016, p. 174), é a potência do humano que, construída na realidade do comando e da exploração, das lutas e das resistências, é justamente aquele que pode promover a ruptura com os exercícios de poder que esmagam a multidão dos pobres, dos excluídos, dos explorados e das formas de vidas não humanas que, se inúteis ao acúmulo de riquezas, são apagadas. Esse comum 
está além das figuras soberanas do privado e do público, que foram criadas na utopia e na transcendência, no projeto idealista das filosofias políticas que encaram o comum como filho profano e impuro da Criação, mas na constituição da práxis coletiva que busca, justamente, dar forma ao comum (SANTIAGO, 2012, p. 33). Ele se encontra longe das cristalizações divinais e dos fetiches uniformizantes do ser, sendo um encontro de modos de ser, potentes e em constante construção, da parte e do todo. Anti-Hobbes, porque recusa a transferência do poder ao soberano, o apagamento das singularidades e a expropriação do comum (NEGRI, 2016, p. 165).

Hardt e Negri (2005) recorrem ao pragmatismo americano de William James e John Dewey, para entender, na modernidade, o conceito de hábito como aquilo que é o comum na prática, e que permite, justamente, a produção do comum, uma "ontologia da prática social em comum" (HARDT; NEGRI, 2005, p. 258). E pensando junto à teoria queer no pensamento de Judith Butler, na "pós-modernidade", o hábito passa a dar lugar - ou compartilhar de modo coadjuvante, pois a produção material continua - à performance, seja linguística ou cultural, como produtora do comum imaterial, e que dá conta, inclusive, de toda produção biopolítica, e não somente econômica, como na modernidade (HARDT, NEGRI, 2005, p. 259-260). As singularidades, ao interagirem, compartilharem e comunicarem suas práticas e seus saberes na dinâmica social, são produtoras incessantes daquilo que é o comum. Comum como noção, comum como prática coletiva, comum como aquilo que não é superior ou cumulativo, mas simultâneo (CHAUÍ, 2016, p. 246). Noções comuns como razão, agir em comum como agir racionalmente:

Por ser ação e não paixão, a razão traz a constantia afetiva que mantém e aumenta a cohaerentia interna de cada parte humana singular e por isso o preceito racional primordial da convenientia é um afeto ativo, a fortitudo: cada um, ao esforçar-se para conservar ser buscando o útil próprio (firmeza), busca o útil para outrem (generosidade), isto é, coisas que convêm com a natureza de cada um e dos demais e que por isso são necessariamente boas (CHAUí, 2016, p. 441).

$\mathrm{O}$ agir em comum como o combate à servidão por meio da força dos afetos e dos encontros alegres, e na vida em sociedade comum como muito mais vantajosa para os seres humanos do que desvantajosa (SPINOZA, 2017, EIV, P35, Esc., p. 178), a qual, ao máximo, buscará uma vida em concórdia. De modo que aquilo que é mal à sociedade humana (SPINOZA, 2017, EIV, P40, Dem., p. 184), a extrema discórdia, não promova o exercício de submissão, tirania e opressão. O comum como constância nos afetos, coerência singular e conveniência como parte do coletivo, na busca do que é "de utilidade comum a todos" (SPINOZA, 2017, EIV, P18, Esc., p. 169).

É em um contexto de uma situação global em comum de pobreza, exploração, tentativa de apagamento das culturas locais, precarização do trabalho, ampliação da desigualdade social, destruição dos ambientes e paisagens naturais e culturais que Hardt e Negri (2005, p. 277) afirmam que aquilo que produz a multidão política que resiste ao assédio do capital global e da ampliação das tiranias globais é justamente a mobilização do comum. A qual, inclusive, é epistemológica, pois ao permitir a comunicação compartilhada das experiências em comum, fazem com que o conhecimento desse comum venha à tona em forma, lembram os autores, de uma foucaultiana "insurreição dos saberes" (HARDT; NEGRI, 2016, p. 142-143).

Um projeto político globalizado que busca fortalecer a comunicação entre os mais diversos movimentos globais contra a expropriação daquilo que é comum. São revoltas e lutas que, ao perceberem justamente que os processos de ação do capital estão internacionalizados, passam a se comunicar e mobilizar, levando esses pontos de resistência a tecer redes de ação. Ação global em comum. Desde as lutas anticoloniais, passando pelos movimentos antiapartheid, os zapatistas de Chiapas, os movimentos LGBTQI+ os Fóruns Sociais Mundiais, os movimentos ecologistas. Entre esses, pode-se incluir movimentos camponeses pela agroecologia, a luta pelos atingidos por barragens, os ciclistas urbanos, os defensores de baleias do Sea Shepherd, os grupos mascarados defensores dos animais, entre outros.

Sendo assim, Hardt e Negri (2018) sugerem que para entender a construção do saber em comum dessa multidão, é preciso partir "de baixo" - pensando "de baixo" não somente como o periférico e o marginal, mas daquilo que é expropriado do que lhe é comum - e das resistências, dos 
processos que gritam e se mobilizam contra a ação daquilo que é público e privado em detrimento do que é o comum. Como evocado no começo desse texto, a partir das críticas de Spinoza ao pensamento político, é necessário entender a política não a partir dos projetos idealistas da filosofia platonizada, que insiste em dar aos coletivos um projeto divinizado a se alcançar, mas a partir daquilo que existe, na materialidade, na imanência, na natureza. A influência de Maquiavel e Spinoza faz com que Hardt e Negri insistam, portanto, em entender a ação política a partir dos processos de resistência, de busca por liberação, das lutas contra a servidão e a destruição dos modos comunais.

Dardot e Laval (2017), ao interpretarem e dissecarem o sentido do comum - e o spinozismo comunizado - de Hardt e Negri, permitem ao conceito uma ampliação de sua proposta epistemológica e metodológica, buscando no federalismo proudhoniano e na sua crítica à propriedade um exercício de caracterizar o agir em comum como poder instituinte ${ }^{2}$. O qual, longe de promover uma recusa da materialidade do mundo, utiliza-a - em especial, nos espaços públicos - como meio de transformação e revolução. A construção da política do comum não pode, de nenhum modo, esquecer sua força multitudinária, baseada nos modos singulares das partes que constituem os coletivos humanos, na construção de intensivas e imanentes democracias.

\section{O COMUM DA EDUCAÇÃO AMBIENTAL}

Nesse sentido é que tanto Hardt e Negri quanto Dardot e Laval sugerem, de modo muito próximo, que os movimentos ecologistas são expoentes das lutas pelo comum. Os primeiros evocam o conceito de sombra, sugerido por Rachel Carson, para enfatizar o silêncio sobre as milhares de catástrofes causadas pela ação humana sobre o planeta, que corroem constantemente não somente as paisagens naturais, mas as próprias condições da vida humana, em especial a dos pobres (HARDT; NEGRI, 2018, p. 343) E, apesar de questões mais abrangentes, midiáticas e de preocupação institucional por parte das Nações Unidas - como o aquecimento global - que de uma forma ou outra também atentam contra o comum, lutas menores - como a guerra contra a apropriação da água na Bolívia, as batalhas pela praça Tanzin em Istambul, e a constante resistência dos ameríndios e camponeses brasileiros - alertam para o fato de que a apropriação daquilo que é o comum é uma problemática global e abrangente. A práxis do comum sugere recuperar o que é o comum, tanto em relação aos bens materiais (DARDOT; LAVAL, 2017, p. 103), quanto àquilo que permite a formação de singularidades e coletividades não aprisionadas em lógicas universais ou discursos únicos, que impedem que alternativas a um capital predatório e necrófago sejam pensadas e construídas.

E é a partir da referência à Primavera Silenciosa de Rachel Carson (1907-1964) feita por Hardt e Negri, tanto para enaltecer a ideia de "violência ecológica" sofrida, em primeiro lugar - e em comum - pelos pobres e os indígenas, quanto para entender as lutas ecológicas e os movimentos ecologistas como exercícios de resistência em comum é que esse texto busca propor que a educação ambiental e as perspectivas ecologistas em educação se constroem, primeiramente, nas lutas em comum. As quais, entre tantos aspectos, têm na obra e militância da bióloga estadunidense ${ }^{3}$, ao mínimo, uma inspiração em comum.

A construção da educação ambiental, como um movimento filosófico e político na educação e na ecologia política, precisa evitar ser entendida exclusivamente a partir da normalização e institucionalização da educação ambiental como política pública. Se a educação ambiental, pensada como herdeira do legado dos movimentos ecologistas, busca a transformação radical das sociedades, não é através da lei e da aceitação pela governamentalidade - ou do seu protagonismo da mesma - que a

\footnotetext{
2 Apesar da discordância conceitual que Dardot e Laval desenvolvem, em especial, à noção de poder constituinte de Antonio Negri, sugerindo o termo instituinte - se baseando naquilo que Castoriadis havia sugerido como duas dimensões do imaginário, o instituído e o instituinte - como dimensão política da ação do comum, as duas perspectivas são incisivas na denúncia dos perigos da cooptação e anulação das forças da multidão pelos poderes constituídos/instituídos.

${ }^{3}$ Que faleceu, em 1964, em decorrência de um câncer, provavelmente ocasionado pelas pesquisas que Rachel Carson realizou, por muitos anos, como os pesticidas que ela denunciou serem os principais responsáveis pela grande matança de animais silvestres, nos anos 50 e 60, nos EUA.
} 
história pode ser contada, já que a principal crítica é justamente contra as tragédias promovidas pela ação do capital protegido pelo aparato estatal.

Diversas discussões já foram realizadas no sentido de atentar para o fato de que a institucionalização pode promover o risco não somente de tornar a educação ambiental uma exótica ferramenta de dominação, mas, inclusive, de enfraquecer ou até anular toda a força política de sua proposta (REIGOTA, 2008; BARCHI, 2016; MACHADO e MORAES, 2019). Além disso, e apesar do sentimento de vitória política, imposição institucional e aceitação coletiva que a legislação sobre a educação ambiental parece estabelecer, a mudança dos quadros políticos mostra que, em simples canetadas, não há garantias de que a institucionalização possa fazer da governança o principal promotor de educação ambiental.

É o caso, por exemplo, da assinatura do decreto 9672, de 2 de janeiro de 2019, que extinguiu a Diretoria de Educação Ambiental do Ministério do Meio Ambiente, não levando em consideração, inclusive, a Lei 9797/99 de Política Pública de Educação Ambiental, de 1999 - e consequentemente o Decreto 4281/2002, que regulamenta essa lei - que obriga ao poder público a manutenção de tal órgãos. Tanto a Lei de 1999 quanto o Decreto de 2002 estabeleceram a obrigatoriedade da criação de um Órgão Gestor que seria o responsável pela implantação da Política Pública de Educação Ambiental, e envolveu os Ministérios do Meio Ambiente e da Educação. Pelo lado do primeiro, havia uma Diretoria de Educação Ambiental, submetida diretamente à Secretaria Executiva do Ministério; e pelo lado da Educação, a coordenação e gestão ocorreram através da Coordenação Geral de Educação Ambiental, sob a administração da Secretaria de Educação Continuada, Alfabetização e Diversidade, também extinta no início de 2019.

Mas também não é a canetada que irá destruí-la. E uma das intenções desse texto é colaborar na construção de perspectivas que ajudem a pensar o inverso. Pois pensar a construção da educação ambiental brasileira a partir de uma história e uma condição que a restrinja, em sua construção, ao estabelecimento de uma série de normativas jurisdicionais, é empobrecê-la, enfraquecêla e, principalmente, tirá-la de sua imanente dimensão aquilo que justamente possibilitou - ou pensando "spinozamente", viu a necessidade - o desenvolvimento dos seus primeiros passos: o comum.

É preciso entender a educação ambiental, em primeiro lugar, como uma exigência de movimentos ecologistas e educacionais, que, em comum - além de suas diferenças e multiplicidades internas e externas - têm a preocupação com a compreensão sobre as causas que constroem e ampliam a problemática ambiental, os efeitos sobre a vida individual e coletiva humana, sobre a vida não humana e suas inter-relações, e, sobretudo, a tentativa de produzir e aperfeiçoar as alternativas aos processos de destruição e morte que o capitalismo promove em suas dinâmicas globais e locais.

Ao pensar sobre a construção comum da educação ambiental brasileira, é necessário evidenciar, entre outras muitas manifestações, a militância de ecologistas como José Lutzenberger na construção de uma ética para o convívio ecológico e "ecossustentável" (PEREIRA, 2019); ou de Aziz Ab'Saber em sua incansável luta na compreensão e proteção das paisagens brasileiras (AB'SABER, 2007); de Frans Krajcberg na proteção à floresta a partir da produção e exposição das obras artísticas com as árvores incineradas (OLIVEIRA, 2015); de Augusto Ruschi, o qual, a partir de sua visão ampla de ciências, buscava a conservação de "um mínimo de natureza", para as gerações atuais e presentes (GONÇALVES, 2018), além da proteção, claro, de seus inestimáveis beija-flores; de Miguel Abellá, em sua luta quixotesca contra a poluição de São Paulo (ABELLÁ, 2000); de Cacilda Lanuza e Fernando Gabeira (MACHADO; MORAES, 2019), de Ana Maria Primavesi, precursora da agroecologia no Brasil, entre outros. A partir das mais distintas ações, cada um desses e dessas ecologistas, em comum, influenciaram, com intensidades diferentes, a construção do campo da educação ambiental brasileira.

Assim como resgata Reigota (2016), a presença de Felix Guattari no Brasil, especialmente nos anos 80, que com a leitura de seus textos, e as interlocuções promovidas a partir delas, influenciou e permitiu a construção de uma "ecosofia tropical" (REIGOTA, 2016, p. 83), mesmo que o silêncio sobre essas passagens, na construção dos parâmetros que deram à educação ambiental brasileira o espaço governamental, tentasse apagar esse fato. Nesse sentido, pensando ainda com Reigota (2010), é necessário pensar na contribuição política, educacional, acadêmica e ecológica de todos aqueles que estão "nas margens" e, pensando o mundo a partir de suas trajetórias comuns e cotidianas, criam e 
produzem novos e outros sentidos de mundo, em diálogo, consonância e dissonância do saber acadêmico.

É preciso incluir nessa construção comum da ecologia política e da educação ambiental no país a união das pessoas que criaram as diversas organizações não governamentais de defesa do meio ambiente. É o caso da SOS Mata Atlântica, que a partir de meados dos anos 80, iniciou uma gigantesca ação de propaganda para conscientizar a população brasileira sobre a importância da Floresta Tropical Atlântica. E também da Funatura a qual, em parceria com o Zoológico de Sorocaba, promoveu, por muito tempo, um dos mais reconhecidos trabalhos de educação ambiental no país, entre o fim dos anos 70 e meados dos anos 90, tendo em vista construir, junto a um máximo possível de crianças e adultos, outra visão dos animais e da natureza (MERGULHÃO, 1998).

Ainda é necessário que as contribuições das mais diversas manifestações culturais e contraculturais sejam também compreendidas como contributivas do campo da educação ambiental, pensada não somente como dispositivo de criação de condutas e consenso ao redor de uma determinada ecologia, impositiva de uma moral única de vida (HENNING; SILVA, 2018), mas como uma potência criativa que abrange uma série de ecologias (GODOY, 2008) e educações menores (GALLO, 2002). É o caso dos saberes insurrectos dos discursos ecologistas das bandas de música extrema (BARCHI, 2017), os quais, a partir de um radical anarquismo que imputa ao Estado e ao capital as mazelas ambientais, disseminam uma perspectiva ecológica muito particular entre seu público admirador, que ao se espalhar pelas capas e letras, especialmente das bandas punk, hardcore e grindcore do Brasil, influenciada por bandas internacionais do estilo, permite circular uma crítica ambientalista muito incisiva. Os álbuns "Verde Não Desmate" da banda Cólera, "Brasil" do Ratos de Porão, ambos lançados no ano seguinte do assassinato de Chico Mendes, em 1989, e "Arise" do Sepultura, lançado no ano anterior à RIO-92, em 1991, são alguns dos expoentes mais conhecidos.

As quatro dimensões citadas, apesar de sua amplitude, são somente uma parcela da multiplicidade de saberes "em comum" compartilhados, e que, mesmo de modo não tão sincronizado, organizado e sistematizado, acaba por trazer aquilo que é o de mais comum à educação ambiental: o alerta para a catástrofe ecológica, o esclarecimento sobre os processos de degradação e predação ambiental, e a criação conjunta de formas de frear, reverter, impedir, ou mesmo, como sugere Krenak (2019), adiar o fim do mundo. A grande quantidade de experiências e perspectivas em educação ambiental está presente nos textos e depoimentos nos mais diversos eventos específicos da área, assim como nos artigos e ensaios de revistas acadêmicas específicas ${ }^{4}$, caracterizando a multiplicidade dos saberes em comum que vem compondo o campo da educação ambiental brasileira.

Esse comum da educação ambiental pode ser compreendido não como um mito fundador que precisa constantemente voltar à sua origem para que ela tenha sua autenticidade e eficácia devidamente comprovada, ao se igualar ao original. Ela precisa, de modo inverso, ser capaz de perceber como se dá a produção da ecologia e da educação, como um conjunto de saberes e desejos políticos em comum, para que justamente não se permita mergulhar em um buraco sem fim nefasto, que é a obediência cega à parâmetros "ecológicos" estabelecidos por exercícios de poderes políticos que a venham utilizar como dispositivo e ferramenta de dominação e submissão.

O comum da educação ambiental, em primeiro lugar, é sua força de recusa ao fatalismo e a resiliência. Ao buscar impedir a trajetória destrutiva das sociedades contemporâneas, não se submeter à falsa noção de que o ser humano por natureza é destrutivo e que seu fim é a autodestruição, e que existem formas de reversão das tendências autofágicas das comunidades humanas, a educação ambiental, em suas imensas diferenças, tem no discurso ecológico do enfrentamento ao desenfreado desenvolvimento econômico uma de suas mais compartilhadas propostas de pensar e agir.

Em segundo lugar, o comum da educação ambiental é seu amplo escopo de contribuições de outras esferas do conhecimento, e não somente da ciência acadêmica. Não que dentro da pesquisa

\footnotetext{
${ }^{4}$ Além de revistas especializadas, como a REMEA (Revista Eletrônica do Mestrado em Educação Ambiental) e Ambiente \& Educação, ambas da Universidade Federal do Rio Grande (FURG), a RevBEA (Revista Brasileira de Educação Ambiental), da Universidade Federal de São Paulo (Unifesp), existe uma grande quantidade de dossiês em periódicos nacionais, além de produções sobre educação ambiental espalhadas por revistas dos mais diversos temas.

Educação em Revista|Belo Horizonte|v.36|e234279|2020
} 
acadêmica, a educação ambiental esteja fechada a poucas esferas do saber, como Biologia, Geografia ou Filosofia. Dos Estudos Culturais à Química, da História à Farmácia, dos Estudos sobre Racismo e Gênero até a Engenharia e Arquitetura, da Antropologia ao Direito, o campo se amplia e não se recusa a receber as mais diversas noções do saber científico. No entanto, é na recepção do saber indígena, quilombola, ribeirinho, camponês, periférico, marginal, artístico, esportivo e das culturas extremas que a educação ambiental é também composta de múltiplos saberes e noções, que compõe um campo diverso, plural e cada vez mais tecido em redes de ações de resistência e criação de novos modos de existência.

E em terceiro, o comum da educação ambiental, especialmente no Brasil, tem a forte influência de Paulo Freire (ARAÚJO FREIRE, 2003; REIGOTA, 2013; SILVA 2018; DICKMANN, 2019), que se não necessariamente abordou de forma sistemática a educação ambiental como uma preocupação epistemológica e metodológica definida, tem em diversos de seus textos uma série de lembranças e experimentações ecológicas narradas de modo muito gentil e afetuosa. Um exemplo está no belíssimo "A sombra desta mangueira" (FREIRE, 2012), que teve seu lançamento em 1995, cujo texto é carregado de uma ecologia muito própria, constituída de memórias e experiências que também construíram e potencializaram Paulo Freire como o educador que foi:

As árvores sempre me atraíram. As suas frondes arredondadas, a variedade do seu verde, sua sombra aconchegante, o cheiro de suas flores, de seus frutos, a ondulação de seus galhos mais intensa, menos intensa em função de sua resistência ao vento. As boas-vindas que suas sombras sempre dão a quem a elas chega, inclusive a passarinhos multicores e cantadores. A bichos, pacatos ou não, que nelas repousam (FREIRE, 2012, p. 25).

Além das ecologias presentes na constituição de si, a indignação contra a desigualdade, a opressão, a destruição dos modos comuns de vida, a banalização da vida (FREIRE, 2000) e a intensa esperança no trabalho educativo pela transformação do mundo ${ }^{5}$, fizeram com que a obra de Paulo Freire na educação ambiental brasileira tivesse um lugar de protagonismo. Tanto em suas perspectivas maiores - institucionais, governamentais - quanto em suas perspectivas menores - libertárias, de recusa, de resistência.

\section{A EDUCAÇÃO AMBIENTAL DO COMUM}

Longe, entretanto, de estabelecer uma dicotomia difusa e enevoada entre capitalismo/estatismo causador da crise ambiental, e entre um ecologismo pseudo anarco-libertário primitivista, garantidor da salvação humana, é preciso pensar a educação ambiental como um campo constituído pelos encontros, pelas conexões, pelas convergências e por aquilo que resultou desses liames, sejam eles mais ou menos duradouros ou entrelaçados. Assim como pelas pelejas, pelas disputas, pelas deserções, pelas rachaduras e pelos exercícios de poder e resistência dentro de seu campo. O qual, como discutido anteriormente, apesar das tentativas de cooptação e cristalização de seus saberes e práticas, não pertence ao Estado, ao Capital ou necessariamente - e somente - à ciência acadêmica, mas ao comum.

E se é do comum que a educação ambiental é constituída, é preciso pensar em estratégias que a impeçam de ser cooptada pelos agentes de poder, sob o risco de apagá-la ou transformá-la em um prática ecogovernamental (MALLETE, 2011) de subserviência às normas ecológicas que não necessariamente ameacem a ordem político econômica vigente. Ou ainda que a mantenham viva nas práticas humanas, pedagógicas ou não, escolares ou não, em momentos em que as preocupações ecológicas e ambientais são brutalmente difamadas e combatidas pela governamentalidade de países como o próprio Brasil, em que desde a extinção dos órgãos promotores da educação ambiental em

\footnotetext{
${ }^{5}$ Cabe ressaltar que o conceito de esperança em Paulo Freire é muito mais um verbo de ação, do que necessariamente a noção que Spinoza criticava como uma brutal paralisadora do fazer humano, a qual servia para garantir a resiliência humana durante os processos de submissão e servidão, que manteriam aos exercícios de poder teológico político divinamente incontestáveis.
} 
esfera federal, até a recusa oficial em ter papel de protagonismo no combate ao aquecimento global, fazem com que ecologistas e educadores ambientais, de colaboradores pela melhoria da qualidade de vida das populações, passem a ser vistos como párias e inimigos do progresso.

Ou seja, é necessário fazer da educação ambiental um exercício em comum, de prática comunal, a qual não somente seja promotora de fazeres e saberes ecológicos, mas que se compreenda como campo ininterrupto, incongelável e, especialmente, imanente. Ligado diretamente à vida das pessoas, das comunidades, do fazer cultural, político, social e econômico do cotidiano. Uma educação ambiental que não seja somente uma esfera especial da educação e da ecologia, ou um exotismo acadêmico e militante de alguns profissionais apaixonados pelas áreas. E que não deixe também de ser isso. Mais do que um nome próprio de um conjunto de práticas acadêmicas e pedagógicas que visem "ecologizar" o mundo, ou um substantivo que seja um campo específico da ciência, é preciso pensar a educação ambiental como movimento, como ação, como verbo.

É nesse sentido que Reigota (2012), ao propor práticas ecológicas na educação - e viceversa - mais como perspectivas ecologistas em educação do que necessariamente uma educação ambiental fechada em si própria, busca fazer com que esse campo seja compreendido a partir da filosofia política da educação. Não somente como uma filosofia de posicionamento político e ideário de movimentos ecologistas e educacionais, mas como um exercício constante de práxis freiriana em educação e ecologia. E nessa constante ativação dessas práticas, é necessário, portanto, pensar na perspectivação ecológica da educação. Assim como poder e resistência são verbos de ação no pensamento foucaultiano, perspectiva precisa ser verbo de ação no pensamento ecológico na educação. A educação ambiental, como verbo, passa a perspectivar ecologicamente a educação.

Preencher a educação dos mais diversos sentidos ecologistas. Não a ecologia que impõe modos de vidas (GODOY, 2018), mas que procure identificar, compreender e fazer ecologias em cada exercício pedagógico. Perspectivar ecologicamente a educação como um constante movimento de compreender relações, interdependências, sujeições, ativações, afecções. Fazer da ecologia na educação um processo de construção constante, não somente de noções comuns, evocando novamente Spinoza, mas de conexões que potencializem a práxis ecológica com um fazer político coletivo de recusa ao fatalismo apocalíptico que a falta de esperança(r) - como verbo de ação, em Paulo Freire - tanto insiste em disseminar.

Perspectivar ecologicamente a educação, pensando em fazer uma educação ambiental do comum, é pensá-la em sua imanência, em como intrínseca à vida humana, em suas necessidades, em suas limitações, e nos perigos que a acometem. Uma educação ambiental do comum que busque tornar as ecologias singulares conectivas, aliadas, potentes, se aglutinando cada vez mais nos processos de ativações e agires ecológicos em comum. Um aprendizado constante, ético-afetivo, pensado como arte de encontro e de recusa aos ditames e vontades soberanas (MERÇON, 2009, p. 80). Perspectivar ecologicamente a educação não é relativizar as mais distintas disparidades, sendo muitas delas criadas sob as superstições, os preconceitos e as divinizações das verdades, mas dar às experiências algumas ferramentas para pensar o mundo a partir daquilo em que a ecologia exerce de melhor, seja como perspectiva política ou como um ramo privilegiado das ciências biológicas, que é a compreensão de qual papel cada ser e de cada elemento no mundo. Perspectivar, nesse caso, é saber, dialogicamente o que é o outro, a partir do outro, sem estabelecer relações verticalizadas de saberes, experiências, ou dimensões do conhecimento.

Uma educação ambiental para o comum é justamente, acompanhando o pensamento de Hardt e Negri (2018, p. 324) sobre as lutas sociais - que entendemos também como um dos papeis dessa educação ambiental - orientá-la para o exercício de uma "comunização". Longe da noção estatizante das repúblicas soviéticas, mas como necessidade de dar a ela a liberdade e a soberania em constantes tomadas de superfícies. Como quando Deleuze resgata Saint-Hilaire para dizer, sob inspiração spinozana, que há somente um animal no mundo, e que suas partes estão interligadas de modo não necessariamente hierárquico ou pressuposto. E quando Viveiros de Castro sugere que é somente ao vestir a roupagem do outro é que se pode sentir, saber e experimentar o que o outro pensa, a partir de sua perspectiva. 
Nesse sentido, é de uma série de noções em comum a partir do qual foi criada, que também se pode pensar a educação ambiental como fenômeno científico, histórico, político e filosófico, assim como um exercício de permeio às outras áreas do conhecimento - e não a matriz impositiva de saberes - em sua profunda preocupação com aquilo que é realmente vivo - por isso sua imanência - é que a educação ambiental, necessariamente, pode encontrar mais forças para garantir e ampliar sua capacidade de transformação, insubmissão, radicalidade, potência e diálogo.

\section{REFERÊNCIAS}

ABELLÁ, Miguel. Militância como filosofia de vida. Educação Ambiental: seis anos de experiência. São Paulo: WWF Brasil, 2000, p. 129-130. Entrevista.

AB'SABER, Aziz Nacib. O que é ser geógrafo: memórias profissionais de Aziz Ab’Saber em depoimento a Cynara Menezes. Rio de Janeiro: Record, 2007.

ARAÚJO FREIRE, Ana Maria. O legado de Paulo Freire à Educação Ambiental. In: NOAL, Fernando Oliveira; BARCELOS, Valdo Hermes de Lima (orgs.). Educação Ambiental e Cidadania: Cenários Brasileiros. Santa Cruz do Sul: EDUNISC, 2003. p. 11-22.

BARCHI, Rodrigo. Educação ambiental e (eco) governamentalidade. Ciênc. educ. (Bauru), Bauru, v. 22, n. 3, p. 635-650, setembro de 2016. Disponível em $<$ http:/ /www.scielo.br/scielo.php?script=sci_arttext\&pid=S1516-

$73132016000300635 \& \operatorname{lng}=$ en\&nrm=iso $>$. acesso em 14 de agosto de 2019.

BARCHI, Rodrigo. O ruído infame das ecologias menores: o grindcore e as relações entre meio ambiente e educação. Revista do Lhiste, Porto Alegre, num.6, vol.4, jan/dez. 2017. p. 179-200. Disponível em: https://seer.ufrgs.br/revistadolhiste/article/view/84969/48950. Acesso em 23 de outubro de 2019.

CHAUÍ, Marilena. Política em Espinosa. São Paulo: Companhia das Letras, 2003.

CHAUÍ, Marilena. Desejo, paixão e ação na ética de Espinosa. São Paulo: Companhia das Letras, 2011.

CHAUÍ, Marilena. A nervura do real: imanência e liberdade em Espinosa, volume II: Liberdade. São Paulo: Companhia das Letras, 2016.

DARDOT, Pierre; LAVAL, Christian. Comum: Ensaio sobre a revolução no século XXI. Trad. Mariana Echalar. São Paulo: Boitempo, 2017.

DELBOS, Victor. O problema moral na filosofia de Spinoza e na Historia do Spinozismo. Trad. Martha de Aratanha. Rio de Janeiro: FGV Editora, 2016.

DELEUZE, Gilles. Espinosa: Filosofia Prática. Trad. Daniel Lins e Fabien Pascal Lins. São Paulo: Escuta, 2002.

DELEUZE, Gilles. Espinosa e o problema da expressão. Trad. GT Deleuze 12. São Paulo: Ed. 34, 2017.

DeLEUZE, Gilles; GUATTARI, Felix. Mil Platôs: capitalismo e esquizofrenia, vol. 4. Trad. Suely Rolnik. São Paulo: Ed. 34, 1997. 
DICKMANN, Ivo; STANQUEVISKI, Claudemir. Pedagogia da resistência: aportes críticos para uma Educação Ambiental Freiriana. Quaestio, Sorocaba, SP, v. 21, n. 1, p. 59-80, jan./abr. 2019.

FREIRE, Paulo. Pedagogia da Indignação: cartas pedagógicas e outros escritos. São Paulo: Editora UNESP, 2000.

FREIRE, Paulo. À sombra desta mangueira. Rio de Janeiro: Civilização Brasileira, 2012.

GALLO, Sílvio. Por uma Educação Menor. Educação \& Realidade, Porto Alegre, v. 27 n. 2, p. 169176, jul./dez. 2002

GODOY, Ana. A menor das ecologias. São Paulo: Editora da Universidade de São Paulo, 2008.

GONÇALVES, Alyne dos Santos Gonçalves. A militância conservacionista de Augusto Ruschi: Práticas científicas e estratégias políticas na construção da Biologia e da Conservação da Natureza no Brasil (1937-1986). 320 f. Tese (Doutorado em História Social das Relações Políticas). Vitória: Universidade Federal do Espírito Santo, 2018.

HARDT, Michael. Gilles Deleuze: Um Aprendizado em Filosofia. Trad. Sueli Cavendish. São Paulo: Ed. 34, 1996

HARDT, Michael; NEGRI, Antonio. Multidão: Guerra e democracia na era do Império. Trad. Clóvis Marques. São Paulo: Record, 2005.

HARDT, Michael; NEGRI, Antonio. Bem-Estar Comum. Trad. Clóvis Marques. São Paulo Record, 2016.

HARDT, Michael; NEGRI, Antonio. Assembly: A organização multitudinária do comum. Trad. Lucas Carpinelli, Jefferson Viel. São Paulo: Editora Filosófica Politéia, 2018.

HENNING, Paula, Corrêa; SILVA, Gisele Ruiz. Rastros da educação ambiental. O dissenso como potência criadora. In: HENNING, Paula Corrêa; MUTZ, Andresa Silva da Costa; VIEIRA, Virgínia Tavares (orgs.). Educações Ambientais Possíveis: Ecos de Michel Foucault para pensar o presente. Curitiba: Appris, 2018. p. 9-16.

KRENAK, Ailton. Ideias para adiar o fim do mundo. São Paulo: Companhia das Letras, 2019.

MACHADO, Carlos Roberto da Silva; MORAES, Bruno Emílio. Educação ambiental crítica: da institucionalização à crise. Quaestio, Sorocaba, SP, v. 21, n. 1, p. 39-58, jan./abr. 2019.

MALLETE, S. Foucault para o próximo século: ecogovernamentalidade. Ecopolítica, São Paulo, n. 1, p. 4-25, 2011. Disponível em: . Acesso em: 13 jan. 2020.

MERÇON, Juliana. Aprendizado ético-afetivo: Uma leiura Spinozana da Educação. Campinas: Editora Alínea, 2009.

MERGULHÃO, Maria Cornélia. Zoológico: Uma sala de aula viva. 144 f. Dissertação (Mestrado em Educação). São Paulo: USP, 1998.

NEGRI, Antonio. A anomalia selvagem: poder e potência em Spinoza. Trad. Raquel Ramalhete. Rio de Janeiro: Ed. 34, 1993. 
NEGRI, Antonio. Espinosa subversivo e outros escritos. Trad. Herivelto Pereira de Souza. Belo Horizonte: Autêntica Editora, 2016.

NEGRI, Antonio. Deleuze e Guattari: uma filosofia para o século XXI. Trad. Jefferson Viel. São Paulo: Editora Filosófica Politéia, 2019.

OCHOA, Carlos; BARAHONA, Ana. El debate entre Cuvier y Geoffroy, y el origen de la homologia y la analogia. Ludus Vitalis, vol. XVII, n. 32, 2009, pp. 37-54. Disponível em: http://www.ludusvitalis.org/ojs/index.php/ludus/article/view/243/235. Acesso em 02 dez. 2019.

OLIVEIRA, Uillian Trindade. Frans Krajcberg: História de vida e processo de Criação. 181 f. tese (Doutorado em Educação). Vitória: Universidade Federal do Espírito Santo, 2015.

ONFRAY, Michel. Contra-história da filosofia: os libertinos barrocos, III. Trad. Eduardo Brandão. São Paulo: Editora WMF Martins Fontes, 2009.

PEREIRA, Elenita Malta. A construção da ética do convívio ecossustentável pelo ambientalista José Lutzenberger (1971-2002). Tempo e Argumento, Florianópolis, v. 11, n. 26, p. 7 - 43, jan./abr. 2019. Disponível em: https://doi.org/10.5965/2175180311262019007. Acesso em 13 dez. 2019.

REIGOTA, Marcos. Educação Ambiental: a emergência de um campo científico. Perspectiva, Florianópolis, v. 30, n. 2, p. 499-520, maio/ago. 2012. Disponível em: https://periodicos.ufsc.br/index.php/perspectiva/article/view/2175-795X.2012v30n2p499. Acesso em 09 de setembro de 2019.

REIGOTA, M. Cidadania e educação ambiental. Psicologia \& Sociedade, Porto Alegre, v. 20, n. esp., p. 61-69, 2008. Disponível em: <http://dx.doi.org/10.1590/S0102-71822008000400009>. Acesso em: 3 nov. 2019.

REIGOTA, Marcos. A contribuição política e pedagógica dos que vem das margens. Teias: Rio de Janeiro, ano 11, n. 21, p. 1-6, jan./abr. 2010. Disponível em: <https://www.epublicacoes.uerj.br/index.php/revistateias/article/view/24105/17083>. Acesso em 15 dez. 2019.

REIGOTA, Marcos. Afetos, educação ambiental e política: Encontros com Nita e Paulo Freire: The Postcolonialist, v. 1, p. 1-5, 2013. Disponível em: <http://postcolonialist.com/culture/afetoseducacao-ambiental-e-politica-encontros-com-nita-e-paulo-freire/>. Acesso em: 20 dez. 2019.

REIGOTA, Marcos. A ecosofia de Félix Guattari e suas conexões tropicais. In: ROMAGUERA, Alda; AMORIM, Antonio Carlos. Conexões: Deleuze e Máquinas e Devires e... Rio de Janeiro: DP et Alli, 2016. p. 77-92.

SAINT HILAIRE, Etienne Geoffroy. Princípios de Filosofia Zoológica. Trad. Pablo Ires. Buenos Aires: Cactus, 2009.

SAMPAIO, Shaula Maíra Vicentini. Como criar paisagens em ruínas? Deslocamentos, desconstruções e insistência de pensar a Educação Ambiental no Antropoceno. Quaestio, Sorocaba, SP, v. 21, n. 1, p. 19-38, jan./abr. 2019.

SANTIAGO, Homero. As aproximações entre Spinoza, Nietzsche e Antonio Negri: entrevista a Marcia Junges. IHU On-line Revista do Instituto Humanitas Unisinos, São Leopoldo, n. 397, ano XII, 06 ago 2012. p. 31-35. Disponível em: http://www.ihuonline.unisinos.br/media/pdf/IHUOnlineEdicao397.pdf. Acesso em: 20 ago 2018. 
SILVA, Marilena Loureiro da. Trajetórias de educação ambiental na Amazônia Paraense: releituras e inquietações do legado freiriano na formação do educador. Quaestio, Sorocaba, SP, v. 20, n. 2, p. 341 355, ago. 2018. Disponível em: https://doi.org/10.22483/2177-5796.2018v20n2p341-355. Acesso em 18 nov. 2019.

SPINOZA, Benedictus de. Ética. Trad. Tomáz Tadeu. Belo Horizonte: Editora Autêntica, 2017.

SPINOZA, Benedictus de. Tratado Político: Trad. Diogo Pires Aurélio. São Paulo: Editora WMF Martins Fontes, 2009.

SPINOZA, Benedictus de. Obra completa II: correspondência completa e vida. Trad. J. Guinsburg, Newton Cunha. Org. J. Guinsburg, Newton Cunha, Roberto Romano. São Paulo: Perspectiva, 2014.

STERN, Ana Luiza Saramago. A imaginação no poder: obediência política e servidão em Espinosa. Rio de Janeiro: Contraponto: Ed. PUC-Rio, 2016.

SUHAMY, Ariel. Spinoza por las bestias. Trad. Sebastián Puente. Ciudad Autônoma de Buenos Aires: Cactus, 2016.

VIVEIROS DE CASTRO, Eduardo. A inconstância da alma selvagem e outros ensaios de antropologia. São Paulo: Cosac Naify, 2002.

VIVEIROS DE CASTRO, Eduardo. Metafísicas canibais: Elementos para uma antropologia pósestrutural. São Paulo: Cosac Naify: N-1 Edições, 2015.

ZOURABICHVILI, François. Spinoza: Uma física del pensamento. Trad. Sebastián Puente. Ciudad Autônoma de Buenos Aires, 2014.

Submetido: $27 / 02 / 2020$

Aprovado: $27 / 10 / 2020$ 